\title{
Blood cell count is not a significant predictor of survival in bladder cancer after radical cystectomy
}

\author{
Andy $^{12^{*}}$, Fauriski Febrian Prapiska ${ }^{2}$, Ginanda Putra Siregar ${ }^{2}$, Syah Mirsya Warli ${ }^{3}$, \\ and Bungaran Sihombing ${ }^{2}$
}

\begin{abstract}
BACKGROUND
Radical cystectomy (RC) is the gold standard treatment for muscle-invasive bladder carcinoma. A predictive factor is needed for the aggressive approach as it could lead to overtreatment. Elevated blood cell count (BCC) markers are reported to have a significant association with poor outcomes in several types of malignancy. Neutrophil-to-lymphocyte-ratio (NLR) and plateletto-lymphocyte ratio (PLR) are well-known inexpensive and effective representative markers of inflammatory conditions. This study aimed to determine the $\mathrm{BCC}$ as a predictive factor of overall survival (OS) in patients with bladder carcinoma (BC) after RC.
\end{abstract}

\section{METHODS}

A retrospective cohort study was conducted involving 26 patients who had undergone RC. The demographic characteristics and BCC markers such as hemoglobin (Hb). NLR, PLR and lymphocyte/monocyte ratio (LMR) were collected. The patients were categorized based on the BCC marker value ( $\geq$ median and $<$ median). Kaplan-Meier survival analysis was done to determine overall survival (OS) on BCC markers. The association between patient demographics and one-year survival was also determined using Mantel-Cox (Log-rank) method.

\section{RESULTS} analysis, none of the demographic characteristics was found to be a significant predictor of one-year and overall survival $(p>0.05)$. Hemoglobin, NLR, PLR and LMR were not significant predictors of one-year survival and $\operatorname{OS}(\mathrm{p}>0.05)$.

\section{CONCLUSIONS}

The BCC was not a significant predictive factor of survival in patients with bladder cancer after radical cystectomy.

Keywords: Blood cell count, predictive factor, radical cystectomy, survival, retrospective cohort
Among the 26 patients, the mean age was $55.6 \pm 12.9$ years. On univariate

${ }^{1}$ Department of Urology, Faculty of Medicine, Universitas Indonesia Jakarta

${ }^{2}$ Division of Urology, Department of Surgery, Faculty of Medicine, Universitas Sumatera Utara - Haji Adam Malik General Hospital, Medan ${ }^{3}$ Department of Urology, Faculty of Medicine, Universitas Sumatera Utara - Universitas Sumatera Utara Hospital, Medan

*Correspondence:

Andy

Department of Urology

Faculty of Medicine,

Universitas Sumatera Utara

H. Adam Malik General Hospital

Medan

Bunga Lau Street No.17, Medan,

Sumatera Utara, 20136

+6221- 8360143

Email:andy.andy.2590@gmail.com ORCID ID: 0000-0001-7005-8871

Date of first submission, December 21, 2020

Date of final revised submission, August 6, 2021

Date of acceptance, August 14, 2021

This open access article is distributed under a Creative Commons AttributionNon Commercial-Share Alike 4.0 International License

Cite this article as: Andy, Prapiska FF, Siregar GP, Warli SM, Sihombing B. Blood cell count is not a significant predictor of survival in bladder cancer after radical cystectomy. Univ Med 2021;40:148-56. doi: 10.18051/UnivMed.2021.v40.151159.

DOI: http://dx.doi.org/10.18051/UnivMed.2021.v40.151-159

$$
\text { Copyright@Author(s) - }
$$




\section{INTRODUCTION}

Bladder carcinoma (BC) is the seventh most prevalent neoplasm worldwide and the most prevalent cancer of the urinary tract with an incidence of 550,000 every year. ${ }^{(1,2)}$ In 2018 , approximately 200,000 deaths were due to BC with 3.2 per 100,000 deaths among males and 0.9 per 100,000 deaths among females every year. ${ }^{(2)}$

Radical cystectomy (RC) is currently the gold standard treatment for muscle-invasive bladder carcinoma (MIBC) or recurrent highgrade non-muscle invasive bladder carcinoma (NMIBC). Radical cystectomy has also been found to be the most suitable treatment for stage II and stage III BC. Currently, 10-year causespecific survival (CSS) rates after RC are only $70 \%$ for NMIBC and $40-60 \%$ for MIBC. ${ }^{(3-5)} \mathrm{A}$ systematic review and meta-analysis found $23.3 \%$ overall probability of tumor recurrence 1 year after RC, $38.3 \%$ at 5 years, $44.8 \%$ at 10 years, and $48.6 \%$ at 20 years. ${ }^{(6)}$ The overall prognosis of the recurrent patients was also very poor with $80 \%$ of all the patients dying within 1 year and only $3.5 \%$ surviving for more than 5 years. ${ }^{(6)}$ This indicates that a more aggressive approach is needed for oncological outcome improvement for both MIBC and recurrent highgrade NMIBC. ${ }^{(7)}$ However, a non-selective aggressive treatment can lead to overtreatment of people with a good prognosis thus a predictive factor is needed. ${ }^{(7)}$

Current evidence assumes that systemic inflammatory response is triggered by the cancer, resulting in changes in inflammatory cells. ${ }^{(8)}$ Neutrophilia with thrombocytosis and lymphocytopenia are the main cell changes found in cancer which along with inflammatory mediators promote the tumor microenvironment. ${ }^{(7)}$ Several studies have found an association between several blood cell count (BCC) markers, such as preoperative lymphocyte-to-monocyte ratio (LMR), monocyte-lymphocyte ratio (MLR), platelet-to-lymphocyte ratio (PLR), and neutrophil-to-lymphocyte ratio (NLR), with oncologic outcomes in several neoplastic diseases, including lung, renal, hepatic, breast, and bladder cancer ${ }^{(8)}$ creating an inflammation-based scoring system to predict oncologic outcomes in cancer. ${ }^{(9)}$

Currently, several studies have found a significant association between BCC markers and invasive BC. Luo et al. ${ }^{(7)}$ has found a significant difference in red cell distribution width (RDW), NLR, PLR, and MLR between BC patients and controls. This study has also found NLR to be an independent predictor for $\mathrm{BC}$.

Our study differs from the previous study, in that we determined the association between preoperative $\mathrm{CBC}$ marker values and the overall survival in $\mathrm{BC}$ patients who have undergone RC. This study aimed to determine the BCC as a predictor factor of overall survival (OS) in patients with bladder carcinoma (BC) after RC.

\section{METHODS}

\section{Research design}

This was a retrospective cohort study and was conducted in the Haji Adam Malik North Sumatra General Central Hospital between 2014 and 2019.

\section{Patients}

A total of 26 patients were included in this study (19 male and 7 female) with median age of 57 years. Study subject enrollment followed a twostep method consisting of the selection of RC BC patients with available pre-treatment $\mathrm{BCC}$ biomarker reports and exclusion of patients with one of the following criteria: RC done for salvage, failed RC, and chemoradiation. All subjects were histologically diagnosed with BC.

\section{Data collection}

The data regarding patient characteristics (age, gender, $\mathrm{T}$ stage, $\mathrm{N}$ stage, $\mathrm{M}$ stage, histopathology, smoker status, hydronephrosis) and BCC were obtained from their medical records in 2014-2019. Pretreatment BCC was measured within a week before treatment initiation (median of 6 days, IQR 1/4 2-10 days). 
The date of treatment initiation was defined as the date of RC. Every patient was treated with $\mathrm{RC}$ and none had a history of undergoing neoadjuvant therapy.

We then calculated the NLR, LMR, MLR and PLR based on the patient's BCC data. The NLR was defined as absolute neutrophil count divided by absolute lymphocyte count. Absolute lymphocyte count divided by absolute monocyte count was defined as the LMR. The PLR was calculated by dividing absolute platelet count by absolute lymphocyte count. The MLR was obtained by dividing absolute monocyte count by absolute lymphocyte count.

\section{Clinical outcomes}

Outcomes were measured by one-year and overall survival (OS). Overall survival was calculated as the time from the date of $\mathrm{RC}$ to the date of death regardless of cause. Surviving patients were censored at the date of last contact.

\section{Statistical analysis}

Patient characteristics and distributions of hematological parameters were summarized using descriptive statistics. All numerical variables were dichotomized based on the median of each variable. We then analyzed the association of patient demographics and hematological findings with one-year survival and overall survival using Mantel-Cox (Logrank) test. All significantly associated variables will then be computed using Cox-regression analysis. Statistical analyses were performed using SPSS v23 for Windows. All tests were two-sided and a p-value of $<0.05$ was considered statistically significant.

\section{Ethical clearance}

The study has been approved for ethical clearance by the Ethical Committee, Faculty of Medicine, Universitas Sumatra Utara, under number 247/TGL/KEPKFKUSU-RSUPHAM/ 2020.

\section{RESULTS}

A total of 26 patients were included in this cohort (73\% males, median age 57 years). Patient characteristics such as smoking status, hydronephrosis, histopathology, T stage, $\mathrm{N}$ stage, and CBC panel (leukocyte, lymphocyte, monocyte and platelet counts, NLR, MLR, LMR, PLR) are detailed in Table 1.

\section{Overall survival analysis}

The median survival time of male patients was 127 (9-658) days, relatively higher than that

Table 1. Demographic characteristics, pathological and hematological features of postradical cystectomy patients $(n=26)$

\begin{tabular}{|c|c|}
\hline Characteristic & n (\%) \\
\hline \multicolumn{2}{|l|}{ Gender } \\
\hline Male & $19(73.1)$ \\
\hline Female & $7(26.9)$ \\
\hline Age (years) @ & $55.6 \pm 12.9$ \\
\hline Smoking & $14(60.9)$ \\
\hline Hydronephrosis & $10(41.7)$ \\
\hline \multicolumn{2}{|l|}{ Tumor (T) Stage } \\
\hline $\mathrm{T} 1 / \mathrm{T} 2$ & $7(26.9)$ \\
\hline $\mathrm{T} 3 / \mathrm{T} 4 \mathrm{a}$ & $19(73.1)$ \\
\hline Node $(\mathrm{N})$ involvement & $9(40.9)$ \\
\hline \multicolumn{2}{|l|}{ Histopathological subtype } \\
\hline $\begin{array}{l}\text { Transitional cell } \\
\text { carcinoma }\end{array}$ & $20(90.9)$ \\
\hline $\begin{array}{l}\text { Lympho-mucinous } \\
\text { adenocarcinoma }\end{array}$ & $1(4.5)$ \\
\hline $\begin{array}{l}\text { Papillary urothelial } \\
\text { carcinoma }\end{array}$ & $1(4.5)$ \\
\hline Free tumor edge & $13(56.5)$ \\
\hline Lympho-vascular invasion & $10(43.5)$ \\
\hline Hemoglobin mg/dL $\$$ & $10.2(6.9-13.5)$ \\
\hline Leukocytes $\times 10^{3} / \mu \mathrm{L}^{\$}$ & $8.4(4.7-24.1)$ \\
\hline Neutrophils $\times 10^{3} / \mu \mathrm{L}^{\$}$ & $60.2(2.4-22.8)$ \\
\hline Monocytes $\times 10^{3} / \mu \mathrm{L}^{\$}$ & $8.9(2.9-13.3)$ \\
\hline Lymphocytes $\times 10^{3} / \mathrm{L}^{\$}$ & $1.62(0.4-3.1)$ \\
\hline Platelets $\times 10^{3} / \mu \mathrm{L}^{\$}$ & $337(109-712)$ \\
\hline $\mathrm{NLR}^{\$}$ & $3.89(1.2-50)$ \\
\hline MLR \$ & $0.45(0.2-4.4)$ \\
\hline $\mathrm{LMR}^{\$}$ & $2.21(0.2-4.6)$ \\
\hline PLR $\$$ & $195.08(87.9-818.9)$ \\
\hline
\end{tabular}

$@$ Data presented as Mean \pm SD; \$ Median (Min-Max); NLR : neutrophile-to-lymphocyte ratio; MLR : monocyteto-lymphocyte ratio-monocyte LMR : lymphocyte-tomonocyte-ration; PLR ; platelet-to-lymphocyte ratio 
of female patients 102 (16-162). Patients $<55$ years of age had a longer median survival time than elderly patients [127 (9-658) versus 63.5 (9-620) days]. However, this difference was not found to be statistically significant $(p>0.05)$. We also found that smoking status, hydronephrosis, $\mathrm{T}$ stage, lymph node involvement, carcinoma subtype, tumor margins, and lympho-vascular invasion were not statistically related to the overall patient survival rate $(\mathrm{p}>0.05)$.

Hematologic findings were not found to be significantly associated with overall patient survival. The group of patients with a higher oneyear survival rate also had a longer median survival rate, except for the percentage of neutrophils. The median survival in patients with high neutrophil percentage was 83.5 (9-658) days, longer than in patients with low neutrophil percentage [71 (9 -569) days].

\section{One-year survival analysis}

There were no demographic factors associated with one-year survival. The one-year survival rate of female patients was $14.3 \%$, while that of male patients was $26.7 \%$. However, this difference was not statistically significant ( $>0.05$ ). In addition, there was no association between one-year survival rate and age, but the elderly had a relatively lower one-year survival rate. Details regarding the relationship between characteristics (demography) and patient survival are presented in Table 2. The percentage of patients who survived the first year after radical cystectomy was higher in patients with $\mathrm{Hb} 10.2$ $\mathrm{g} / \mathrm{dL}$; leukocyte count $8.4 \times 10^{3} / \mu \mathrm{L}$; neutrophil, monocyte, and lymphocyte percentage less than $60.2 \%, 8.9 \%$, and $1.62 \%$, respectively; and platelet count less than $337 \times 10^{3} / \mu \mathrm{L}$, was statistically not significant $(\mathrm{p}>0.05)$ (Table 3$)$.

\section{DISCUSSION}

Based on this study, we found that none of the hematological and demographic factors were associated with the survival of bladder cancer patients after radical cystectomy. Although no significant association was found, we note that median survival was relatively higher in patients with hemoglobin less than $10.200 \mathrm{~g} / \mathrm{dL}$, leukocyte count higher than $8.401 \times 10^{3} / \mu \mathrm{L}$, neutrophil count higher than $66.85 \%$, monocyte count lower than $8.85 \%$, lymphocyte count more than $18.7 \%$, platelet count less than $364 \times 10^{3} / \mu \mathrm{L}$, NLR less than 3.576, MLR more than 0.447, LMR less than 2.238, and PLR more than 17.739.

We documented that patients with NLR $<3.576$ had a relatively higher median survival rate. According to previous studies, NLR and dNLR have prognostic value and can be used to predict survival in a large group of cancer patients. ${ }^{(10)}$ Luo et al. ${ }^{(11)}$ also reported a significant difference in RDW, NLR, PLR, and MLR between bladder cancer patients and controls. Furthermore, they found NLR to be an independent predictor for bladder cancer patients' survival. The present study confirmed that leukocyte values might hold important information for predicting bladder cancer severity and bladder cancer patient survival rate. Several inflammation-based prognostic scores that measure changes in circulating inflammatory cells using BCC markers, including preoperative NLR, PLR, MLR, and LMR, have been reported to have an association with oncologic outcomes in several cancers, including lung, renal, hepatic, breast, and colorectal cancer. ${ }^{(12)}$

The role of $\mathrm{BCC}$ as a potential predictive factor in cancer is based on the relationship between cancer and the inflammatory process. ${ }^{(13)}$ The inflammatory process could promote carcinogenesis through oxidative and nitrative damage of macromolecules and epigenetic alterations. ${ }^{(14)}$ Reactive oxygen species/reactive nitrogen species produced by inflammatory cells can lead to damage in biomacromolecules such as DNA, proteins, and lipids. ${ }^{(15,16)}$ Epigenetic alteration in inflammation could cause an alteration in gene expression, such as aberrant DNA methylation and dysregulation of microRNA, which could lead to the promotion of carcinogenesis. ${ }^{(17)}$ Several studies have also observed the induction of a systemic 


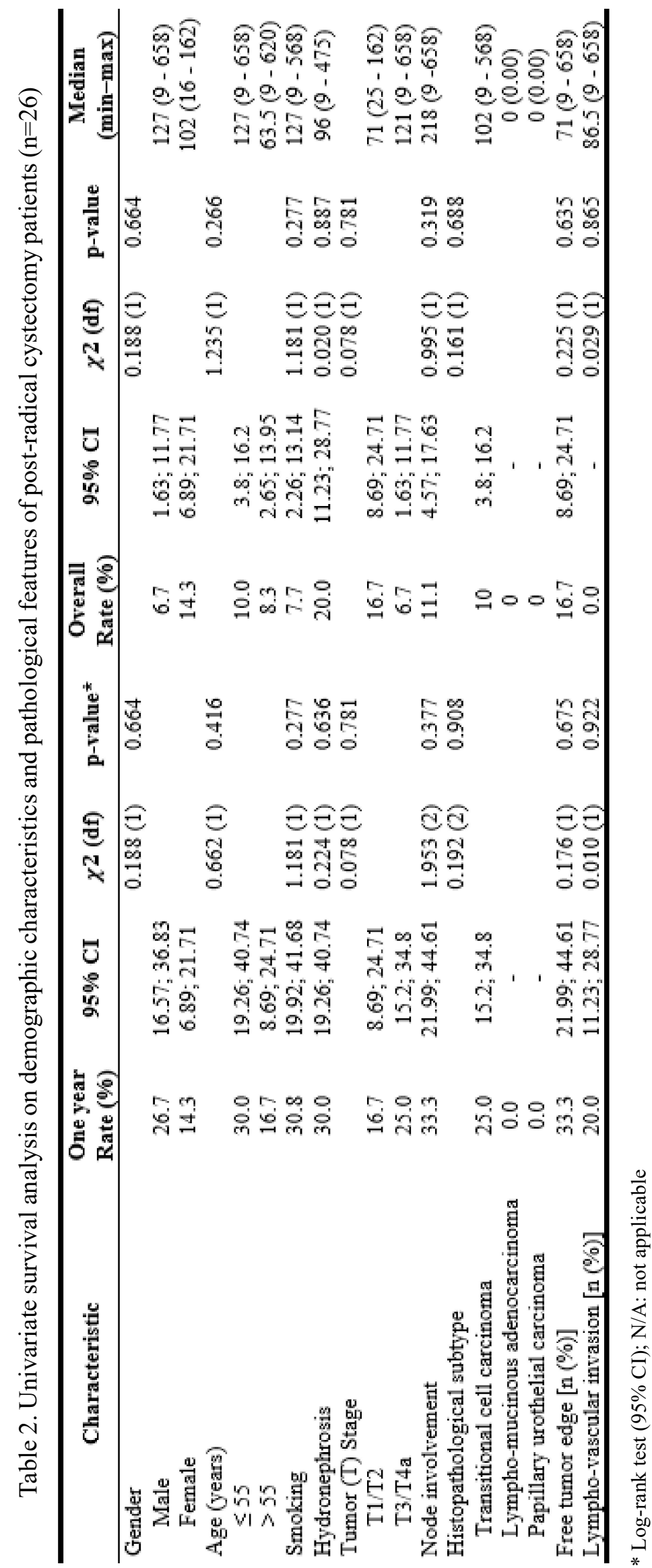




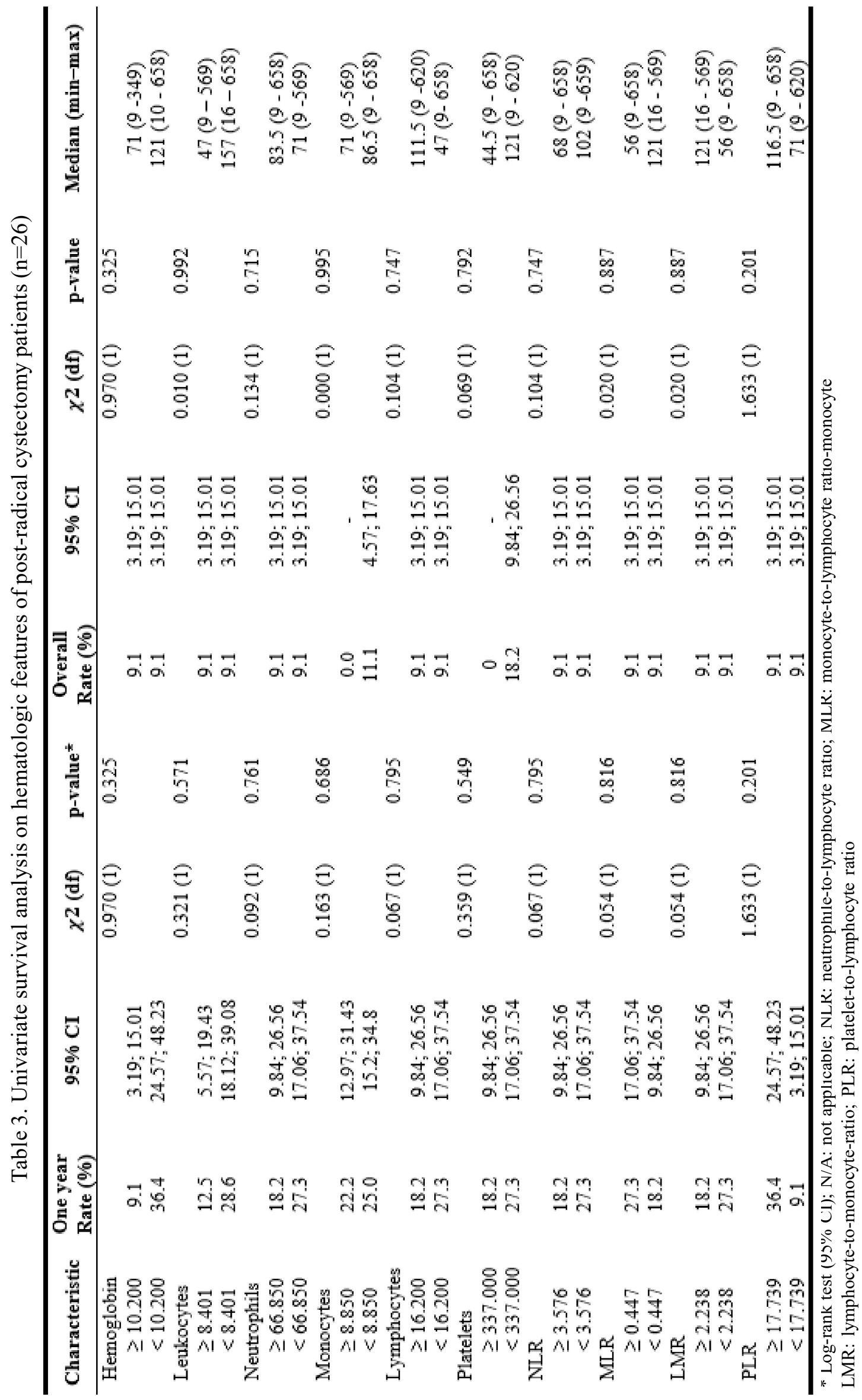


inflammatory response by cancer leading to changes in circulating inflammatory cells which could trigger the growth, maturation, and differentiation of cells within the tumor microenvironment thus causing carcinogenesis. ${ }^{(18)}$

Previous studies have reported NLR as a predictive biomarker for recurrence-free postradical cystectomy cancer-specific survival and overall survival as it has an essential role in immunity and inflammation in cancer development and progression. ${ }^{(19)}$ A higher NLR means a higher innate immune response as compared to an adaptive immune response which leads to neutrophil overactivity that promotes carcinogenesis in pre-malignant lesions as a result of reactive oxygen species production, growth factor secretion, angiogenesis promotion, and metastasis promotion by the neutrophils. ${ }^{(8)} \mathrm{On}$ the other hand, T and B lymphocytes have an antitumor response thus a lower NLR would inhibit carcinogenesis as there are more inhibitory mechanisms compared to the promoting mechanisms. ${ }^{(15)}$

Although most studies suggests that NLR elevation is associated with worse clinical outcomes, some studies have also found a higher survival probability in patients with higher NLR. ${ }^{(20)}$ A study done by Lee et al. ${ }^{(21)}$ which includes patients with metastatic pancreatic cancer has found a significantly higher survival probability for NLR $<1.89$ compared to NLR $\geq 1.89$. A systematic review and meta-analysis showed similar results, in that elevated pretreatment NLR predicted poorer OS in colorectal cancer. ${ }^{(22)}$

The imbalance in the patient's tumor stage demographics, as most samples have T3/T4a stage cancer, is thought to be the main reason for the different results. Cancer stage has been associated with worse survival, therefore, could create a sampling bias where most patients have a bad prognosis to start with. In our study, the age of the patients is normally distributed, thus it does not seem to be a bias even though it has been reported to be a bad prognostic factor in previous studies.
The limitation of this study was that it did not evaluate the contact length and height of the tumor. Increased in leukocyte value could be linear with tumor contact length and tumor height. The wider the tumor, the more the amount of inflammatory agents produced. This applies to tumor height (which reflects tumor degree of invasiveness) as well. Besides, the limited number of patients evaluated during the study might also have contributed to the results we reported. Therefore, future studies with a larger sample size should be conducted, and include ultrasound evaluation in the research to confirm this finding and hypothesis.

\section{CONCLUSIONS}

In this study, we found no significant association of hematological and demographic conditions with post-radical cystectomy patient survival.

\section{CONFLICT OF INTEREST}

Competing interests: no relevant disclosures.

\section{ACKNOWLEDGEMENTS}

The authors would like to thank all staff of the Urology Division of Haji Adam Malik Hospital, Medan, Indonesia, for their continuous support toward us during the writing period of this study. The authors are also grateful to all medical record staff of Haji Adam Malik Hospital, for permission to access the data needed to finish this study.

\section{CONTRIBUTORS}

A contributed to concept, design, definition of intellectual content, literature search, clinical studies, experimental studies, data acquisition, data analysis, statistical analysis, manuscript preparation, and acted as the guarantor of this study. FFP contributed to design, manuscript 
preparation, editing, and review. GPS contributed to concept, definition of intellectual content, data analysis and manuscript review. SMW contributed to concept, definition of intellectual content, manuscript editing, and manuscript review. BSH contributed to concept and definition of intellectual content. All authors have read and approved the final manuscript.

\section{REFERENCES}

1. Kaseb H, Aeddula NR. Bladder cancer. Treasure Island (FL): StatPearls Publishing; 2020.

2. Richters A, Aben KKH, Kiemeney LALM. The global burden of urinary bladder cancer: an update. World J Urol 2019;38:1895-904. doi: 10.1007/s00345-019-02984-4.

3. Wahafu W, Liu S, Xu W, et al. The long-term efficacy of one-shot neoadjuvant intra-arterial chemotherapy combined with radical cystectomy versus radical cystectomy alone for bladder cancer: a propensity-score matching study. BMC Urol 2019;19:117. https://doi.org/10.1186/s12894019-0552-7.

4. Çelen S, Kaygýsýz O, Vurupkan H, Yavapcaoðlu Ý. Laparoscopic versus open radical cystectomy in the treatment of locally advanced T3 and T4 bladder cancer: Perioperative and mid-term oncological outcomes. Turk J Urol 2020;46:123-8. doi: 10.5152/tud.2020.19077.

5. Pane K, Mirabelli P, Coppola L, Illiano E, Salvatore M, Franzese M. New roadmaps for non-muscleinvasive bladder cancer with unfavorable prognosis. Front Chem 2020;8:600. doi: 10.3389/ fchem.2020.00600.

6. McAlpine K, Fergusson DA, Breau RH, et al. Radiotherapy with radical cystectomy for bladder cancer: a systematic review and meta-analysis. Can Urol Assoc J 2018;12:351-60. doi: 10.5489/ cuaj.5244.

7. Bhindi B, Hermanns T, Wei Y, et al. Identification of the best complete blood count-based predictors for bladder cancer outcomes in patients undergoing radical cystectomy. Br J Cancer 2016; 114:207-12. doi: 10.1038/bjc.2015.432.

8. Rajwa P, Życzkowski M, Paradysz A, Bujak K, Bryniarski P. Evaluation of the prognostic value of LMR, PLR, NLR, and dNLR in urothelial bladder cancer patients treated with radical cystectomy. Eur Rev Med Pharmacol Sci 2018;22:3027-37. doi: 10.26355/eurrev 20180515060.

9. Kumar R, Geuna E, Michalarea V, et al. The neutrophil-lymphocyte ratio and its utilisation for the management of cancer patients in early clinical trials. Br J Cancer 2015;112:1157-65. https://doi.org/10.1038/bjc.2015.67.

10. Proctor MJ, McMillan DC, Morrison DS, Fletcher CD, Horgan PG, Clarke SJ. A derived neutrophil to lymphocyte ratio predicts survival in patients with cancer. Br J Cancer 2012;107:695-9. doi: 10.1038/ bjc.2012.292.

11. Gonzalez H, Hagerling C, Werb Z. Roles of the immune system in cancer: from tumor initiation to metastatic progression. Genes Dev 2018;32:126784. doi: $10.1101 / \operatorname{gad} .314617 .118$.

12. Zhou X, Du Y, Huang Z, et al. Prognostic value of PLR in various cancers: a meta-analysis. PLoS One 2014;9:e101119. doi: 10.1371/journal.pone. 0101119.

13. Luo Y, Shi X, Li W, et al. Evaluation of the clinical value of hematological parameters in patients with urothelial carcinoma of the bladder. Medicine (Baltimore) 2018;97:e0351. doi: 10.1097/MD. 0000000000010351.

14. Hanahan D, Weinberg RA. Hallmarks of cancer: the next generation. Cell 2011;4;144:646-74. doi: 10.1016/j.cell.2011.02.013.

15. Shalapour S, Karin M. Immunity, inflammation, and cancer: an eternal fight between good and evil. J Clin Invest 2015;125:3347-55. doi: 10.1172/ JCI80007.

16. Lee SM, Russell A, Hellawell G. Predictive value of pretreatment inflammation-based prognostic scores (neutrophil-to-lymphocyte ratio, plateletto-lymphocyte ratio, and lymphocyte-tomonocyte ratio) for invasive bladder carcinoma. Korean J Urol 2015;56:749-55. doi: 10.4111/ kju.2015.56.11.749.

17. Thanan R, Oikawa S, Yongvanit P et al. Inflammation-induced protein carbonylation contributes to poor prognosis for cholangiocarcinoma. Free Radic Biol Med 2012; 52:1465-72. doi: 10.1016/j.freeradbiomed.2012. 01.018 .

18. Thanan R, Pairojkul C, Pinlaor S, et al. Inflammation-related DNA damage and expression of CD133 and Oct3/4 in cholangiocarcinoma patients with poor prognosis. Free Radic Biol Med 2013;65:1464-72. doi: 10.1016/j. freeradbiomed.2013.07.034.

19. Mossel DM, Moganti K, Riabov V, et al. Epigenetic regulation of S100A9 and S100A12 expression in monocyte-macrophage system in hyperglycemic conditions. Front Immunol 2020;11:1071. doi: 10.3389/fimmu.2020.01071.

20. Kuderer NM, Poniewierski MS, Culakova E, et al. Predictors of venous thromboembolism and early mortality in lung cancer: results from a global 
prospective study (CANTARISK). Oncologist 2018;23:247-55. doi: 10.1634/theoncologist.20170205.

21. Lee BM, Chung SY, Chang JS, Lee KJ, Seon J. The neutrophil-lymphocyte ratio and plateletlymphocyte ratio are prognostic factors in patients with locally advanced pancreatic cancer treated with chemoradiotherapy. Gut Liver 2018; 12:342-52. https://doi.org/10.5009/gnl17216.

22. Li MX, Liu XM, Zhang XF, et al. Prognostic role of neutrophil-to-lymphocyte ratio in colorectal cancer: a systematic review and meta-analysis. Int J Cancer 2014;134:2403-13. doi: 10.1002/ ijc. 28536 . 